\title{
Bat Problems
}

\author{
R.E. Stebbings
}

How to protect 950 bat species worldwide is the problem of the Chiroptera Specialist Group of the IUCN's Survival Service Commission(SSC), which was set up in 1976. The Group's Chairman, Dr R.E. Stebbings, has highlighted the sort of problems they face by three examples: the endemic fruit bat Pteropus rodricencis on Rodrigues Island in the Indian Ocean; the small insectivorous grey bat. Myotis grisescens in the USA, and the common vampire bat Desmodus rotundus of Latin America.

\section{Rodrigues Fruit Bat}

The Rodrigues fruit bat, an attractive 300 -gm bat, ranging in colour from a blond silvery grey through rufous reds to almost black, needs a variety of sheltered trees for roosting and feeding. But forest on Rodrigues has been seriously depleted for firewood and in clearing ground for crops, and this, coupled with periodic devastating cyclones, when trees are blown down and bats get killed, had reduced the bats to fewer than 100 by the mid 1970s. In early 1979, however, there were about 150 , which may be the present maximum carrying capacity of the forest, but a severe cyclone in February 1979 reduced numbers by half to about 70 bats.

In 1976 Gerald Durrell, with the permission of the Mauritius Government, collected 10 bats for captive breeding by the Jersey Wildlife Preservation Trust. Nothing was known about this bat's breeding biology, but nevertheless, three years later, the 10 original bats were still thriving in Jersey Zoo, and so also were all 15 young from 15 births - a remarkable achievement.

However, the problem remains of how to increase the number of bats on Rodrigues. The obvious solution is tree-planting to increase the amount of suitable forest, but is this practicable in an already crowded island? Similar problems occur on many other islands in the Indian and Pacific Oceans.

\section{Grey Bat}

The grey bat, of Missouri and Kentucky south to Alabama, is an example of the vulnerability of apparently common species. Highly gregarious, roosting only in caves and forming colonies of up to 300,000 , this bat is now limited to nine major caves, one of which holds two-thirds of the species. The most important caves lie along river valleys, and therefore are vulnerable to flooding, or blocked entrances by rock falls, and vital feeding areas in the river valleys could be lost through reservoir construction. Thus although the species still exists in relatively large numbers one major disaster could result in their becoming nearly extinct.

\section{Vampire Bat}

The common vampire of Latin America increased greatly following European colonisation and the introduction of domestic stock. Vampires debilitate animals through blood loss and by transmitting diseases, but some control methods have been disastrous, leading to total destruction of caves and other 


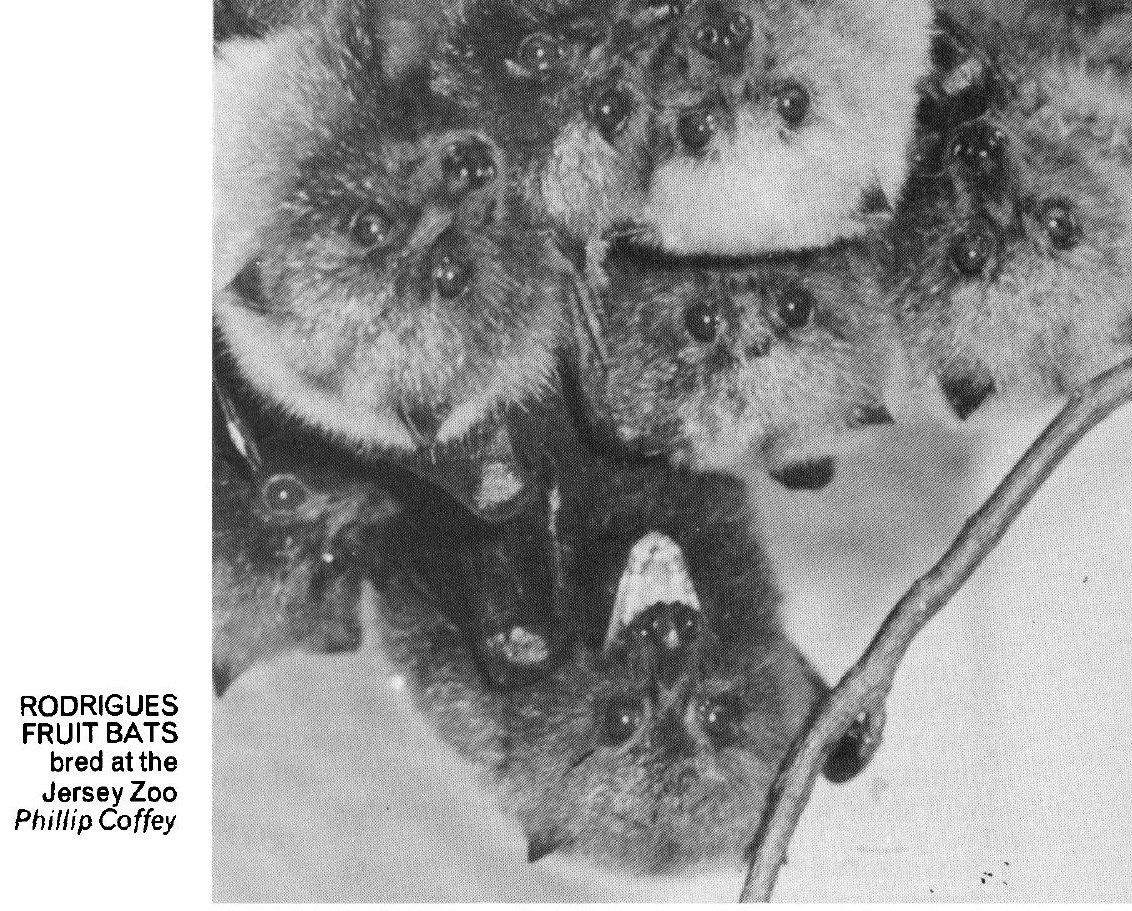

roosts, often where there were no vampires. Other caves were fumigated or treated with jelly containing strychnine and anticoagulants so that any creatures, not just vampires, coming into contact would die. More recently some cattle have been injected with sublethal quantities of anticoagulant which kills vampires feeding on them. All these methods have killed some vampires but they have also killed many non-target bats and other animals. We urgently need a safe species-specific control method that subsistence farmers and government agencies can easily operate.

\section{The Wrong Ways}

In temperate regions people are generally apprehensive or superstitious about bats, and colonies are often deliberately killed in buildings; they are also accidentally killed during treatment of timbers against wood-boring insects or fungi. These colonies often contain all the breeding females of a species from several hundred square miles, and even if not all are killed the very slow reproductive rate (maximum of one per year) prevents a rapid recovery. If bats must be removed from buildings the only solution is to seal all entrances in autumn and winter when the bats are away. Bats do not normally cause damage or serious inconvenience to people, and public education about the habits of bats is one of the Chiroptera Specialist Group's most important tasks.

Dr R.E. Stebbings, FPS, London Zoo, Regents Park, London NW1.

\section{Arabian Oryx in Qatar}

The Ruler of Qatar, Sheikh Khalifa Bin Hamad al-Thani, takes a keen personal interest in the preservation of the Arabian oryx in his country, and has developed four farms where he keeps oryx herds: Shahanayya, recently visited by HM the Queen, and intended to become the Qatar Government National Park, has 20; Wukair has 18; Nuarzer has 4 , and Traina 8 . There are still 32 oryx on the property of the late Sheikh Hassim Bin Hamad al-Thani. 